\title{
Recreational scuba divers' knowledge regarding the audiological consequences of the sport
}

\author{
Dhanashree Pillay (M Communication Pathology) \\ Nastasha P Jardine (Final-year student) \\ University of the Witwatersrand, Johannesburg
}

\begin{abstract}
Background: The sport of scuba diving may be associated with possible injuries, especially those concerning the auditory system. Research available focuses on the implications of recreational scuba diving on the auditory system. However, there is a lack of information regarding the knowledge of recreational scuba divers with regard to the audiological consequences of this sport. Method: The aim of this study was to determine whether scuba divers have knowledge pertaining to the consequences of the sport on the auditory system. Thirty-five participants were purposefully selected; their qualifications ranged from an open water diver to a course director. A mixed-method design was implemented in this study with the use of a questionnaire.

Results: Forty per cent of the participants were given only the basic medical clearance form to complete; the full medical pack was not made available. However, $97 \%$ of the participants signed the medical clearance. One participant did not know that a medical clearance form was required. There were $82 \%$ of the participants who had audiological complications subsequent to diving; these individuals did not seek help from an audiologist and continued to dive.

Conclusion: There is a need for awareness regarding the effects of diving on the auditory system as participants in this study were not fully aware of the risks of the sport in relation to the ear. The results suggest that participants who experience ear difficulties after dives, do not have sufficient knowledge regarding the ear and the professional who is qualified to assess and manage the difficulties.
\end{abstract}

\section{Introduction}

Diving is a popular sport despite the high risks involved. ${ }^{1}$ The sport allows children and adults to obtain the first level of qualification, a junior dive certificate for children and an open water certificate for adults. ${ }^{2}$ The social aspect of this sport is evident as there are a large

\section{CORRESPONDENCE:}

Dhanashree Pillay

Speech Pathology \& Audiology

Private Bag 3

2050 Wits

Tel: $011717-4581$

E-mail: Dhanashree.pillay@wits.ac.za number of divers worldwide. ${ }^{2}$ The Professional Association of Diving Instructors (PADI) and the National Association of Underwater Instructors (NAUI) have the largest recreational diving membership and diver training organisation. ${ }^{3}$ These associations were originally only available to the USA, but the popularity of the sport required the expansion to the rest of the world. According to these associations it is mandatory for all potential scuba divers to complete a medical examination and a questionnaire prior to beginning the course. ${ }^{4}$

The medical examination must include ear history of the potential dive student. ${ }^{5}$ There are several factors concerning the ears that would disqualify a diver from continuing with the sport. These factors include perforated eardrums, surgery to the ear, chronic or acute otitis media, equalising problems, vestibular dysfunction and hearing loss. ${ }^{6}$ In scuba diving the ear is the vital organ responsible for the equalisation of pressure during ascent and descent between ambient water pressure and the external auditory canal, middle ear and paranasal sinuses. ${ }^{7}$ Failure to equalise correctly may result in pain and rupture of the occluded space, with disabling and possible lethal consequences. ${ }^{8}$ Previously ruptured but healed round or oval window membranes are at an increased risk of rupture due to failure to equalise pressure or due to marked over-pressurisation during vigorous or explosive Valsalva manoeuvres. ${ }^{2}$ The analysis and decision concerning a prospective diver's medical suitability rests with the examining physician. ${ }^{5}$ However, it is the responsibility of the diver to provide accurate information concerning his/her earrelated history. Subsequent to the clearance from the physician, the prospective diver is allowed to begin the diving course. According to Du Plessis et al. middle-ear barotrauma (MEBT) is the most common medical complication in diving. Exposure to the underwater environment is associated with several unique disorders, such as ear decompression sickness and barotraumas that may require recompression in a hyperbaric chamber. ${ }^{9}$ Increasing pressure during descent reduces the volume of the paranasal sinuses and middle ear which, if not properly equalised, will sustain injury due to barotraumas. ${ }^{11}$ The greatest volume change occurs between zero and 10 metres of the dive; ${ }^{2}$ at this depth every diver is exposed to possible damage of the audiological system. Divers will need to dive to depths of approximately 45 metres to equal the total volume change produced during the first 10 metres of descent, ${ }^{12}$ indicating why most diving injuries occur during shallow dives. ${ }^{13}$

Modern recreational scuba divers perform multiple dives, ${ }^{14}$ therefore increasing the risk of damage to the auditory system. Literature suggests that there are implications of scuba diving for the auditory system. However, there is a gap in the information regarding the divers' knowledge about these implications. The main objective of this study was to bridge that gap and consequently determine the way forward to reduce the audiological effects of diving on the growing number of recreational scuba divers in South Africa. The general aim of the study was to determine the knowledge of recreational scuba 
divers with regard to the auditory effects of the sport. The specific aims of the study were to determine:

- whether recreational scuba divers read the medical clearance package prior to the scuba divers' course, paying special attention to the information provided on the ear

- whether recreational scuba divers understand the correct procedure for equalising their ears

- whether the recreational diver is aware of the implications of not equalising the ear correctly

- what precautions are taken by recreational scuba divers to protect their ears, prior to diving

- whether the recreational scuba diver presents with audiological abnormalities related to diving, i.e. tinnitus, sensorineural hearing loss, vertigo and barotrauma

- the actions of a recreational diver, should they experience an audiological abnormality, after diving.

\section{Methodology}

\section{Research design}

A mixed-method design was implemented in this research study. The qualitative aspect of the study offered a participant the freedom to express his or her thoughts, feelings and experiences. ${ }^{15}$ The quantitative facet was used to analyse the data obtained in the closedended sections of the questionnaire. ${ }^{16}$

\section{Description of participants}

Participants were selected from dive schools within the Gauteng region using purposeful sampling ${ }^{17}$ to ensure that the individuals met the selection criteria. Thirty-five divers responded to the study. A breakdown of the participants' age is given in Table I.

\begin{tabular}{lcc}
\multicolumn{3}{l}{ TABLE I. Age distribution of participants } \\
\hline $\begin{array}{l}\text { Age range of partici- } \\
\text { pants }\end{array}$ & $\begin{array}{c}\text { Number of fe- } \\
\text { male participants }\end{array}$ & $\begin{array}{c}\text { Number of male } \\
\text { participants }\end{array}$ \\
15 - 19 years & 1 & 4 \\
20 - 24 years & 5 & 6 \\
25 - 29 years & 3 & 4 \\
30 - 34 years & 2 & 2 \\
35 - 39 years & 0 & 1 \\
40 - 44 years & 2 & 3 \\
$45-49$ years & 0 & 1 \\
50 - 54 years & 0 & 1
\end{tabular}

The participants had a range of dive qualifications as shown in Table II. There were 10 participants who had a masters qualification or higher.

\section{Inclusion criteria}

The criteria were the following:

- The participant needed to be 18 years or older.

- The participant needed to have the open water diver certificate as the minimum diving qualification.

- The participant may not have any medical qualification or allied medical qualification regarding the ear, nose or throat.

All participants within this study met all three requirements.

\section{TABLE II. Qualification of participants}

\begin{tabular}{lccc}
\hline Level of qualification & $\begin{array}{c}\text { Male partici- } \\
\text { pants }\end{array}$ & $\begin{array}{c}\text { Female par- } \\
\text { ticipants }\end{array}$ & $\begin{array}{c}\text { Total } \\
\text { Open water }\end{array}$ \\
Adventure diver & 1 & 4 & 7 \\
Advanced open water & 4 & 1 & 2 \\
Rescue diver & 7 & 3 & 7 \\
Master scuba diver & 5 & 2 & 9 \\
Master instructor & 1 & 3 & 8 \\
Course director & 1 & 0 & 1 \\
Total & 22 & 0 & 1 \\
& & 13 & 35
\end{tabular}

\section{Procedure}

The researcher used a self-constructed questionnaire. Open and closed format questions were utilised ${ }^{18}$ as it provided unprompted opinions from the participants, particularly as each participant had their own responses based on personal experience and level of qualification and training, thereby achieving a variety of responses that were broad and thus truly reflected the opinions of each participant. $^{19}$

\section{Data analysis}

Descriptive statistics were used to present the qualitative information obtained, therefore describing the behaviour of a subject without influencing it in any way. ${ }^{18}$

\section{Ethical consideration}

This study was approved by the Human Research Non-Medical Ethics Committee at the University of the Witwatersrand. Each participant had the opportunity to carefully consider the risks and benefits of participating in the study. ${ }^{20}$ All participants completed the consent form.

\section{Results and discussion}

Results obtained are discussed in terms of the sub-aims of the study.

Sub-aim (i): To determine whether recreational scuba divers read the medical clearance package prior to the scuba divers' course

Forty eight per cent of participants were informed verbally, by their dive instructors, about the medical clearance package. However, $40 \%$ of participants were given only the basic medical sheets that required a signature. Sixty per cent of participants were given the entire medical package to read and complete. The medical pack is utilised to determine if a doctor should examine the learner diver before participating in the recreational sport. The medical pack consists of a questionnaire pertaining to medical pathologies that may provide a contraindication prior to the dive. ${ }^{21}$

Twenty per cent of the participants completed the informed consent required despite not reading the information from the medical info pack as it was not deemed imperative to the dive. Five per cent of the participants indicated that they did not complete their own medical information and $17 \%$ just filled out the sheets wherever they were told to. One participant did not know that a medical clearance was required thus did not give formal consent to participate in the sport. Hence this participant started the course with inadequate knowledge of the risks associated with the sport. These 
results indicate that a large percentage of scuba divers in this study were not fully aware of the specific risks associated with the sport as depicted in the medical pack. ${ }^{22}$ It is essential for the dive school to obtain the medical clearance forms to ensure that the individual is fit to dive and the individual has granted permission to participate in the sport with full knowledge of the risks involved. ${ }^{23}$

Sub-aim (ii): To determine whether recreational scuba divers understand the correct procedure of equalising their ears

All 35 participants were aware of the correct procedure when equalising their ears. All participants presented with similar answers when explaining the correct procedure for the equalisation process by pinching the nose closed and blowing gently to relieve the ear cavity of the pressure. ${ }^{7}$ The scuba diver who is not practising the correct equalisation methods is at risk of developing a burst tympanic membrane, bleeding ears, dizziness, nausea and pain. ${ }^{24}$

Sub-aim (iii): To determine whether the recreational diver is aware of the implications of not equalising the ear correctly

Each participant highlighted at least one negative implication placed on the auditory system if not correctly equalised. Table III illustrates the negative implications selected by the participants.

\begin{tabular}{lc} 
TABLE III. Percentage of participants who were \\
aware of the negative implications of diving \\
\hline Negative implication & $\begin{array}{c}\text { Percentage of participants } \\
\text { Burst eardrum }\end{array}$ \\
Hearing loss & $38 \%$ \\
Ear pain & $34 \%$ \\
Barotrauma & $25 \%$ \\
Deafness & $17 \%$ \\
Infection & $14 \%$ \\
Dizziness & $8 \%$ \\
Secretion of fluid & $8 \%$ \\
Vertigo & $5 \%$ \\
Damage to the middle ear & $5 \%$ \\
Increased ear pressure & $5 \%$ \\
Sinus pain & $2 \%$ \\
Nausea & 0 \\
&
\end{tabular}

Excessive force caused by increased water pressure during a dive can cause permanent damage to the ears, ${ }^{7}$ therefore divers need to be fully aware of the negative aspects of the sport. Sixty eight per cent of participants indicated a burst eardrum as a consequence of the sport while $25 \%$ stated barotrauma as a consequence.

Sub-aim (iv): To determine what precautions are taken by recreational scuba divers to protect their ears prior to diving

\section{Hearing assessments}

Eighty-eight per cent of the participants did not have a hearing test before they began scuba diving as they did not feel it essential. Eleven per cent of the participants had consulted an audiologist in the past but the reason for referral was not related to the scuba diving.

\section{Additional precautionary measures}

Forty-six per cent of participants indicated that no precautionary measures are required as protection of the ear was not necessary. Fourteen per cent of the participants indicated their frequent use of ear buds to protect their ears. Eight per cent of participants used eardrops before they dive, placing 2 - 3 drops into their ears half an hour before they dive.

The protection of the hearing system is vital during sporting activities that potentially harm the auditory system, ${ }^{25}$ therefore individuals should ensure that the ears are protected and hearing is monitored when diving.

Sub-aim (v): To determine whether the recreational scuba diver presents with audiological abnormalities related to diving, i.e. tinnitus, sensorineural hearing loss, vertigo and barotrauma

Table IV provides the results obtained from the participants, with regard to the symptoms experienced as a consequence of scuba diving.

Participants indicated that pain and barotrauma were the most common symptoms following the dives. All individuals who experienced a symptom due to diving continued to dive after the symptom subsided. Participants indicated that symptoms were often recurrent. Barotrama affects significant structures within the auditory system such as the tympanic membrane, the eustachian tube, the middle-ear cavity and the inner ear. ${ }^{5}$ Vertigo and dizziness are common symptoms seen in divers, ${ }^{26}$ and this has a drastic effect on the individual due to disorientation and focus.

Sub-aim (vi): To determine the actions of recreational divers who experience an audiological abnormality after diving

Eighty-three per cent of participants who experienced a complication following a dive consulted with a general practitioner (GP). They were all advised to resolve the problems before being able to continue with their diving. However, none was referred to an audiologist. None of the participants in this research study who experienced symptoms related to the auditory system received a hearing evaluation to ensure that no damage occurred within the audiological system.

\section{Conclusion}

Diving is a popular sport that is associated with audiological risks. The results from the current study indicate that scuba divers practise the correct method of equalisation during the dives to protect the auditory system. However, the need for audiological services prior the dive is not a priority. This research found that divers are not fully aware of the professional responsible for any hearing-related issues, therefore the implementation of a mandatory hearing screening for all potential divers would ensure that these individuals know who to go to if a hearing-related difficulty arises after a dive. Awareness of the risks of diving should be made clear to all potential divers to ensure that informed decisions are made. The role of the audiologist is vital in the monitoring and management of the risks associated with the sport. ${ }^{27}$

Medical procedures and policies related to scuba diving should be reviewed to ensure that potential divers are aware of the significant risk of diving to the auditory system. Medical practitioners should ensure that divers who experience trauma to the ear subsequent to diving should be referred for a diagnostic audiological assessment. Audiologists should facilitate changes in the dive medical clearance assessment to include a diagnostic assessment so that the potential 
TABLE IV. Symptoms experienced by the scuba divers

\begin{tabular}{lccc}
\hline Symptoms & Number of participants & $\begin{array}{c}\text { Number of participants whose } \\
\text { symptoms occurred more than } \\
\text { once }\end{array}$ & $\begin{array}{c}\text { Number of participants who } \\
\text { continued diving once the } \\
\text { symptom had disappeared }\end{array}$ \\
$\begin{array}{l}\text { Very painful ear canals } \\
\text { Painful eardrum }\end{array}$ & 8 & 4 & 8 \\
$\begin{array}{l}\text { Burst eardrum } \\
\text { Excretion, other than water coming }\end{array}$ & 3 & 5 & 11 \\
out your ears & 0 & 0 & 3 \\
$\begin{array}{l}\text { Dizziness } \\
\text { Nausea }\end{array}$ & 3 & 0 & 3 \\
$\begin{array}{l}\text { Ringing, buzzing in the ear } \\
\text { Sudden deafness, decreased hear- }\end{array}$ & 5 & 2 & 5 \\
ing sensation & 6 & 2 & 6 \\
$\begin{array}{l}\text { Gradual decline in hearing sensa- } \\
\text { tion }\end{array}$ & 1 & 0 & 1 \\
$\begin{array}{l}\text { Barotrauma (ear pain due to in- } \\
\text { creased pressure) }\end{array}$ & 1 & 3 & 8 \\
Ear infections & 8 & 1 & 6 \\
Cysts, growths & 6 & 0 & 0 \\
\hline
\end{tabular}

diver is assessed and monitored regularly. This process would assist in minimising the ear-related risks involved with the sport.

\section{REFERENCES}

1. Taylor DMD, O'Toole KS, Ryan CM. Experienced scuba divers in Australia and the United States suffer considerable injury and morbidity. Wilderness and Environmental Medicine 2003;14(3):187-193.

2. Shreeves K. The Professional Association of Diving Instructors: Open Water Diver Manual. International PADI, Inc: Rancho Santa Margarita 2008.

3. Malinowski J, Malinowski M. Snorkel Maui and Lana'i: Guide to the Underwater World of Hawaii. Clifornia: Indigo publications, 2000

4. Professional association of diving instructors. The undersea journal. Los Angeles: University of California, 2000.

5. Neuman TS, Thom SR. Physiology and medicine of hyperbaric oxygen therapy. New York: Elsevier health sciences, 2008.

6. NAD. The Noaa Diving Manual: Diving for Science and Technology. USA: Diane publishing, 1992.

7. Graver DK. Scuba diving. Illinois: Human kinetics, 2009

8. Strauss BM, Aksenov IG. Diving science. Illinois: Human kinetics, 2004.

9. Du Plessis C, Fothergill D. Gertner J, Hughes L, Schwaller D. A pilot study evaluating surfactant on eustachian tube function in divers. Military Medicine 2008; 173(12):1225-1232.

10. Bantin J. The scuba diving handbook: the complete guide to safe and exciting scuba diving. Los Angeles: University of California, 2007.

11. Bove AA. Medical disorders related to diving. J Int Care Med 2002;17(2):7586 .

12. Harrill WC. Barotrauma of the middle and inner ear. The Bobby R. Alford Department of Otorhinolaryngology and Communicative Sciences, 1995
13. Aghababian R. Essentials of emergency medicine. Massachusetts: Jones \& Bartlett, 2006

14. Pieterse I. The hearing abilities and middle ear functioning of the recreational scuba diver. Department of Communication Pathology: University of Pretoria, 2006

15. Lewins A, Silver C. Using software in qualitative research: a step-by-step guide. SAGE, 2007.

16. Spector P. Data manipulation with R. Berkeley, California: Springer, 2008.

17. Burns N, Grove SA. The practice of nursing research: conduct, critique and utilization. St Louis, Missouri: Elsevier health sciences, 2005.

18. Balnaves M, Caputi P. Introduction to quantitative research methods: an investigative approach. London: Sage Publications Ltd, 2001.

19. Oppenheim AN. Questionnaire design, interviewing and attitude measurement. London: Pinter, 1992.

20. Marshall C, Rossman GB. Designing qualitative research (4th ed). California: Sage Publications, Inc. 2006

21. Bain C. Malta \& Gozo: Lonely planet Malta (3rd ed). Oakland, California: Lonely planet publishers, 2007.

22. Bove AD, Davis JC. Boves and Davis diving medicine. Philadelphia: Elsevier health science, 2004

23. Young I, Gherardin T. Lonely planet healthy travel Africa. Lonely planet. South pacific underwater medicine society, 2009.

24. Bulenkov SY. Soviet manual of scuba diving. Honolulu, Hawaii: Minerva group, 2004.

25. McKeag D, McKeag DB, Moeller JL . ACSM's primary care sports medicine. Baltimore: Lippincott Williams \& Williams, 2007.

26. Domino FJ. The 5-minute clinical consult 2011. Baltimore: Lippincott Williams \& Williams, 2010

27. Valente M, Hosford-Dunn H, Roeser RJ. Audiology treatment. New York: Thieme, 2008. 